\title{
Neonatal bronchopulmonary dysplasia predicts abnormal pulmonary HRCT scans in long-term survivors of extreme preterm birth
}

\author{
S M Aukland ${ }^{1,2} \mathrm{~K}$ Rosendahl, ${ }^{2,3} \mathrm{C} \mathrm{M}$ Owens, ${ }^{3} \mathrm{~K}$ R Fosse, ${ }^{1} \mathrm{G}$ E Eide, ${ }^{4,5} \mathrm{~T}$ Halvorsen ${ }^{6,7}$
}

${ }^{1}$ Department of Radiology, Haukeland University Hospital, Bergen, Norway; ${ }^{2}$ Department of Surgical Sciences, Section for Radiology, University of Bergen, Norway; ${ }^{3}$ Department of Radiology, Great Ormond Street Hospital for Children, London, UK: ${ }^{4}$ Centre for Clinical Research, Haukeland University Hospital, Bergen, Norway;

${ }^{5}$ Department of Public Health and Primary Health Care, University of Bergen, Norway; ${ }^{6}$ Department of Pediatrics, Haukeland University Hospital, Bergen, Norway; ${ }^{7}$ Department of Clinical Medicine, Section for Pediatrics, University of Bergen, Norway

\section{Correspondence to:}

Dr S M Aukland, Department of Radiology, Haukeland University Hospital, N-5021 Bergen,

Norway; stein.magnus.aukland@ helse-bergen.no

Received 3 July 2008 Accepted 20 December 2008 Published Online First 20 January 2009

\begin{abstract}
Background: There is an increasing understanding that extreme preterm birth carries a risk of long-term pulmonary sequelae. A study was undertaken to investigate if, and in what way, neonatal factors were associated with subsequent abnormalities on pulmonary high-resolution CT (HRCT) scanning and if pulmonary function was related to these abnormalities
\end{abstract}

Methods: HRCT scanning and pulmonary function tests were performed less than 2 weeks apart in 74/86 eligible subjects (86\%) born at a gestational age of $\leqslant 28$ weeks or with a birth weight of $\leqslant 1000 \mathrm{~g}$ within a defined area in Western Norway in $1982-5$ ( $n=42$ ) or $1991-2$

$(n=32)$. Mean age at examination was 18 and 10 years, respectively. HRCT scans were interpreted by a paediatric radiologist blinded to the clinical data using a structured system allowing scores from 0 to 50 .

Results: Lung parenchymal abnormalities were found in 64 subjects (86\%), the median (interquartile range) score being $3.0(1.75-5.0)$ points. Prolonged neonatal requirement for oxygen treatment predicted poor outcome, and an increase of 100 days increased the average HRCT score by 3.8 points $(p<0.001)$. There was also a positive association of the severity of pulmonary function abnormalities with the extent of HRCT abnormalities, exemplified by the relation between forced expiratory volume in $1 \mathrm{~s}$ and total HRCT score $(\beta=-0.090$; $\mathrm{p}<0.001)$.

Conclusions: In area-based cohorts of long-term survivors of extremely preterm birth, prolonged neonatal requirements for oxygen treatment predicted subsequent structural abnormalities on HRCT scans and in pulmonary function, and these two outcome measures were interrelated.

Over the past three decades the survival rates for extremely preterm neonates have increased significantly from $<10 \%$ to $>80 \%$ in developed countries. ${ }^{1-3}$ Despite major advances in treatment, the reported incidence rates for bronchopulmonary dysplasia (BPD) have remained largely unchanged, ${ }^{4}$ and BPD is currently an important cause of chronic lung disease in children and young adults. ${ }^{4-6}$ There is reason to believe that even subtle damage to the lung parenchyma in early life may be a precursor for chronic obstructive pulmonary disease (COPD) in adulthood.' Concerns about long-term outcome for subgroups of BPD survivors were raised as early as in $1990,^{8}$ and have also been expressed in more recent studies. ${ }^{1}$ Large cohorts of these pioneer subjects are about to reach adulthood, allowing thorough assessment of long-term outcomes. In addition to prematurity as such, we still do not fully understand the association between different neonatal factors, events or treatment with pulmonary changes in later life.

We have previously reported on airway abnormalities and pulmonary hyperinflation as well as high-resolution CT (HRCT) findings for two areabased birth cohorts of extremely preterm neonates followed for up to 20 years. ${ }^{9-11}$ Although there is good evidence to suggest an association of prolonged neonatal oxygen requirements with decreased pulmonary function later in life, ${ }^{6} 1112$ similar data for structural lung sequelae are sparse. In the present study we therefore investigated associations between perinatal factors and subsequent structural abnormalities on pulmonary HRCT scans in childhood and early adulthood. We also examined the association between pulmonary function and HRCT findings at follow-up.

\section{METHODS \\ Subjects}

Of the 130 subjects born at a gestational age $\leqslant 28$ weeks or with a birth weight $\leqslant 1000$ g during the two inclusion periods in 1982-5 (first birth cohort) and 1991-2 (second birth cohort), all survivors $(n=86)$ were invited to participate in this study performed in 2001-2. Five eligible preterm individuals could not participate and seven declined to have an HRCT scan performed, leaving 74 subjects (86\%) available for the present study. All preterm individuals were born within a defined region in Western Norway and medical care was provided at the only neonatal intensive care unit in the region (Haukeland University Hospital). Perinatal medical data were accessed from hospital charts and relevant background data from a standardised questionnaire. BPD was classified as suggested by Jobe and Bancalari ${ }^{13}$ — that is, mild or moderate/severe BPD according to requirement for supplemental oxygen at a postnatal age of $\geqslant 28$ days or at a postmenstrual age of $\geqslant 36$ weeks, respectively. Neonatal characteristics of the preterm population are provided in table 1 and their lung function data at follow-up are shown in table 2 . These results are presented and discussed in detail elsewhere. ${ }^{11}$ Briefly, preterm individuals had airway obstruction, airway hyperresponsiveness and pulmonary hyperinflation, which increased with increasing severity of BPD.

\section{Neonatal history and treatment}

Mean (SD) birth weight was 1014 (193) g and 933 (204) g and mean (SD) gestational age was 27.3 (1.4) weeks and 26.7 (1.7) weeks in the first and 
Table 1 Neonatal characteristics of the study population $(n=74)$

\begin{tabular}{|c|c|c|c|c|}
\hline & \multicolumn{4}{|c|}{ Bronchopulmonary dysplasia } \\
\hline & $\begin{array}{l}\text { None } \\
(n=18)\end{array}$ & $\begin{array}{l}\text { Mild } \\
(n=35)\end{array}$ & $\begin{array}{l}\text { Moderate and severe } \\
(\mathrm{n}=21)\end{array}$ & p Value \\
\hline No $(\%)$ girls & $12(63 \%)$ & $20(53 \%)$ & $9(38 \%)$ & $0.123^{*}$ \\
\hline Mean (SD) gestational age (weeks) & $28.1(1.2)$ & $26.7(1.4)$ & $26.3(1.5)$ & $<0.001 \dagger$ \\
\hline Mean (SD) birth weight (g) & $1121.4(160.6)$ & $968.0(201.3)$ & $852.4(169.7)$ & $<0.001 \dagger$ \\
\hline $\begin{array}{l}\text { Median (range) days of ventilator } \\
\text { treatment }\end{array}$ & $0.9(0-4.8)$ & $8.9(0-40.0)$ & $20.5(1.7-54.5)$ & $<0.001 \uparrow$ \\
\hline $\begin{array}{l}\text { Median (range) days of oxygen } \\
\text { therapy }\end{array}$ & $10(1-26)$ & $45(28-71)$ & $103(55-257)$ & $<0.001 \dagger$ \\
\hline
\end{tabular}

second birth cohorts, respectively. In the first inclusion period $39 \%$ of the admitted infants died in the neonatal department compared with $27 \%$ in the second ( $p=0.157$ ).

The senior medical staff responsible for major decisions was largely the same for both periods. Weaning from supplemental oxygen was based on transcutaneous measurements in the 1980s and oximetry in the 1990s. Exogenous surfactant (Exosurf) was available to the second birth cohort and was administered to 15 subjects (47\%), in essence as prescribed for selective administration in the Osiris trial. ${ }^{14}$ Routines for administration of postnatal corticosteroids were similar for the two inclusion periods.

\section{HRCT protocol and interpretation}

The HRCT scans were performed on a General Electric Hi Speed Advantage CT (Milwaukee, USA), obtaining 1.25-mm sections at $10 \mathrm{~mm}$ intervals in inspiration and at $20 \mathrm{~mm}$ intervals in expiration. All scans were interpreted independently by two paediatric radiologists according to a structured scoring scheme. Each lung segment was scored for the presence or absence of the following variables: linear and subpleural triangular opacities (fig 1), decreased lung attenuation (on inspiration and/or expiration, fig 1), bronchial wall thickening, bronchus-toartery-diameter ratio, bullae, emphysema, collapse/consolidation and bronchiectasis. This initial scoring system was robust, with weighted kappa values for the total HRCT score of 0.87 (interobserver) and 0.88 (intraobserver). ${ }^{9}$ A slightly simplified version was used in the present study. The original segmental lung maps from the second reading of observer number 2 (SMA) were re-evaluated. Each lobe (lingula included) was scored according to either the presence (1) or absence (0) of each of the abovementioned variables in any lung segment belonging to that particular lung lobe. Linear and triangular opacities were merged into one variable (ie, the presence of either in any lung segment within a lobe implied a score of 1 for that particular lobe). There was one exception; lungs containing a subsegmental collapse/consolidation were scored as 1 and lungs with segmental involvement were scored as 2 (table 3 ). This system gave a minimum score of 0 (normal) and a maximum score of 50 .

\section{Pulmonary function tests}

Pulmonary function tests were performed within 2 weeks of the HRCT scan. Maximal flow-volume loops and static lung volumes were measured with Vmax 22 and Autobox 6200, respectively (SensorMedics, Yorba Linda, USA), applying standard quality criteria. ${ }^{15}$ Forced expiratory volume in $1 \mathrm{~s}$ $\left(\mathrm{FEV}_{1}\right)$, forced expiratory flow at $50 \%$ and at $25-75 \%$ of forced vital capacity $\left(\mathrm{FEF}_{50}\right.$ and $\mathrm{FEF}_{25-75}$ ), total lung capacity (TLC), residual lung volume (RV) and the ratio RV/TLC were recorded and the values expressed as percentages of predicted. ${ }^{16}{ }^{17}$

\section{Statistical methods}

Lung function data were normally distributed while HRCT scores were not. Group comparisons were done with statistical tests as appropriate (Student $t$ test for lung function data and Mann-Whitney U-test for HRCT scores). The results are reported as means or median values (or both), as appropriate. Simple linear regression analyses were used to study relationships between HRCT scores (response variable) and accessible neonatal variables (antenatal cigarette exposure, antenatal maternal infection, antenatal treatment with corticosteroids, treatment with exogenous surfactant, gestational age at birth, birth weight, closing of a persistent ductus arteriosus, postnatal treatment with corticosteroids, number of days with intermittent positive pressure ventilation, number of days with oxygen treatment). Clinically, we know that that most of these neonatal variables are colinear and we therefore performed a backward stepwise multiple linear regression analysis for total HRCT score. The analysis included those factors from the neonatal period that were significantly related to total HRCT score in simple regression models. Analyses of interaction effects were used to assess if the influence from the examined neonatal

Table 2 Lung function data for the study population $(\mathrm{n}=74)$

\begin{tabular}{|c|c|c|c|}
\hline \multirow[b]{2}{*}{ Lung function variables } & \multicolumn{2}{|c|}{ Bronchopulmonary dysplasia } & \multirow[b]{2}{*}{$p$ Values ( $t$ test) } \\
\hline & $\begin{array}{l}\text { None and mild }(\mathrm{n}=53) \\
\text { Mean }(95 \% \mathrm{Cl})\end{array}$ & $\begin{array}{l}\text { Moderate and severe }(\mathbf{n}=21) \\
\text { Mean }(95 \% \mathrm{CI})\end{array}$ & \\
\hline $\mathrm{FEV}_{1}$ & 89.8 (86.0 to 93.6$)$ & $80.9(76.2$ to 85.7$)$ & 0.004 \\
\hline $\mathrm{FEF}_{50}$ & 83.4 (77.8 to 88.9$)$ & 68.1 (56.4 to 79.8 ) & 0.021 \\
\hline TLC & $102.1(98.1$ to 106.2$)$ & $102.4(97.0$ to 107.8$)$ & 0.935 \\
\hline $\mathrm{RV} / \mathrm{TLC}$ & $21.2(19.6$ to 22.8$)$ & $25.3(22.0$ to 28.5$)$ & 0.026 \\
\hline
\end{tabular}

Lung function variables are expressed as percentages of predicted, except the ratio RV/TLC. The criteria for classification of bronchopulmonary dysplasia are given in the text.

$\mathrm{FEV}_{1}$, forced expiratory volume in $1 \mathrm{~s} ; \mathrm{FEF}_{50}$, forced expiratory flow at $50 \%$ of forced vital capacity; RV, residual volume; TLC, total lung capacity. 

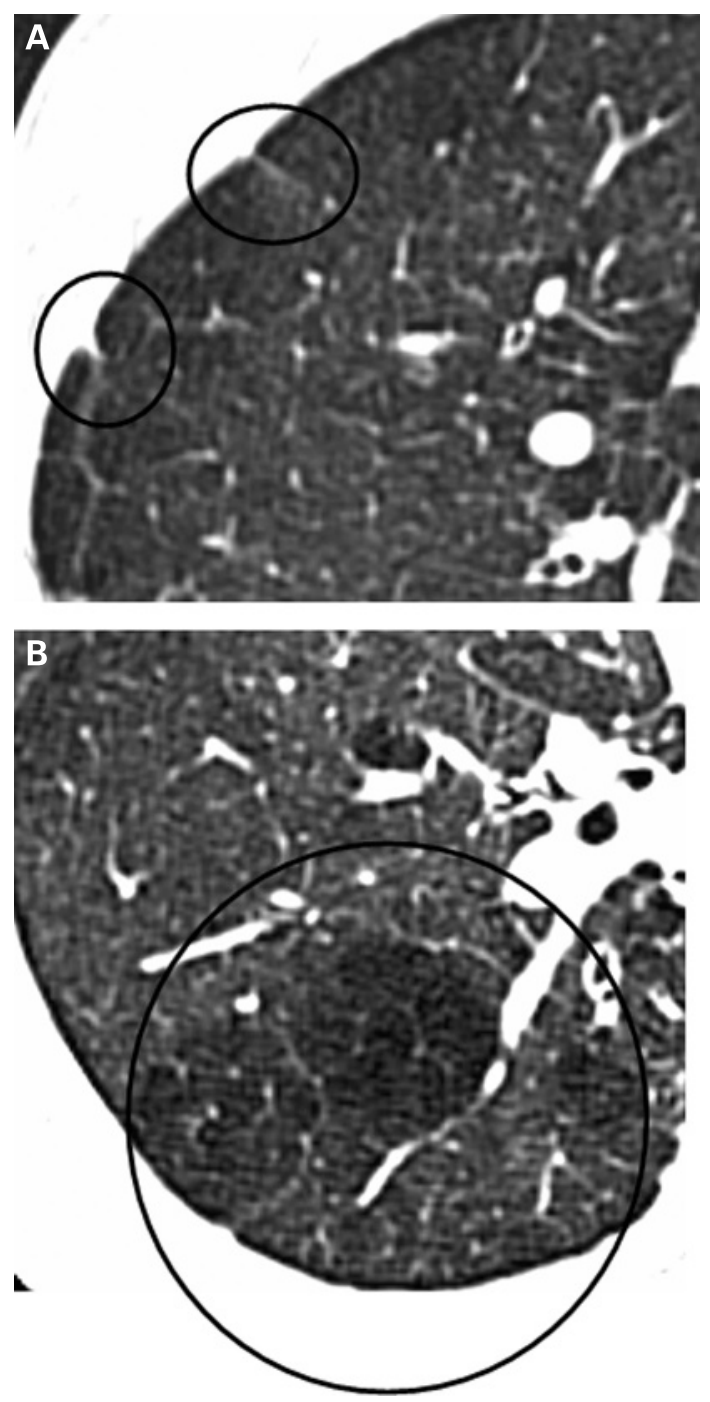

Figure 1 High-resolution CT findings in an 11-year-old boy showing (A) linear and subpleural triangular opacities and (B) hypoattenuated area.

variables differed between the two birth cohorts. ${ }^{18}$ Relationships between HRCT scores (response variable) and lung function data $\left(\mathrm{FEV}_{1}, \mathrm{FEF}_{50}, \mathrm{FEF}_{25-75}\right.$ and $\left.\mathrm{RV} / \mathrm{TLC}\right)$ were studied in simple linear regression models. The results are reported as determination coefficients $\left(R^{2}\right)$ and regression coefficients $(\beta) . R^{2} \times 100$ estimates the percentage of the variability in an outcome variable (eg, total HRCT score) being explained by one or several explanatory variable(s) (eg, $\mathrm{FEV}_{1}$ ) and the adjusted $\mathrm{R}^{2}$ estimates the variance explained "per estimated coefficient" in a multiple linear regression model. The $\beta$ value illustrates the numerical change in an outcome variable, when one explanatory variable changes one unit and other variables are kept unchanged. All statistical tests were performed at a $5 \%$ significance level.

\section{RESULTS}

Neonatal characteristics and lung function data are given in tables 1 and 2. Pathological findings were demonstrated in 64 subjects (86\%). Most of the observed pathology was relatively minor with linear/triangular opacities constituting the majority, seen in $82 \%$ of the cases and contributing $64 \%$ to the total score. Hypoattenuated areas in inspiration were seen in $14 \%$ and hypoattenuated areas in expiration were seem in $26 \%$ of the
Table 3 Revised high-resolution CT scoring system with nine different parameters and a total score of 50

\begin{tabular}{|c|c|c|}
\hline & & Scoring per lobe \\
\hline 1 & Linear or triangular subpleural opacities & $\begin{array}{l}0=\text { absent, } 1=\text { present } \\
\text { Maximum score }=6\end{array}$ \\
\hline 2 & $\begin{array}{l}\text { Decreased pulmonary attenuation } \\
\text { Hypoattenuation ("mosaic perfusion") in inspiration }\end{array}$ & $\begin{array}{l}0=\text { absent, } 1=\text { one lobe } \\
\text { Maximum }=6\end{array}$ \\
\hline 3 & $\begin{array}{l}\text { Decreased pulmonary attenuation } \\
\text { Hypoattenuation ("air trapping") in expiration }\end{array}$ & $\begin{array}{l}0=\text { absent, } 1=\text { one lobe } \\
\text { Maximum }=6\end{array}$ \\
\hline 4 & Bronchus/bronchiole: artery diameter ratio & $\begin{array}{l}0=\text { absent, } 1=\text { one lobe } \\
\text { Maximum }=6\end{array}$ \\
\hline 5 & Bronchiectasies & $\begin{array}{l}0=\text { absent, } 1=\text { one lobe } \\
\text { Maximum }=6\end{array}$ \\
\hline 6 & Peribronchial thickening & $\begin{array}{l}0=\text { absent }, 1=\text { one lobe } \\
\text { Maximum }=6\end{array}$ \\
\hline 7 & Bullae & $\begin{array}{l}0=\text { absent, } 1=\text { one lobe } \\
\text { Maximum }=6\end{array}$ \\
\hline 8 & Emphysema & $\begin{array}{l}0=\text { absent, } 1=\text { one lobe } \\
\text { Maximum }=6\end{array}$ \\
\hline 9 & Collapse/consolidation & $\begin{array}{l}0=\text { absent } \\
1=\text { subsegmental } \\
2=\text { segmental }\end{array}$ \\
\hline
\end{tabular}

cases. The mean (SD) total HRCT score for the whole group was 3.6 (3.0) points (range 0-13). The median (interquartile range, IOR) score was 3.0 (1.75-5.0) points. A higher score was found for the 1982-4 birth cohort than for those born during 1991-2 (mean 4.0 vs 3.2), however the difference was not statistically significant $(p=0.075)$. There was no significant difference according to gender, with mean scores of 4.2 for boys and 3.1 for girls $(p=0.181)$.

\section{Relationship between neonatal factors and HRCT findings}

In linear regression models, neither age at examination nor birth cohort significantly predicted total HRCT score at examination. Numerically, the number of days with oxygen treatment seemed to be of higher importance in the 1991-2 birth cohort than in the 1982-5 cohort, explaining $43 \%$ and $23 \%$, respectively, of the variability in total HRCT score $\left(R^{2}=0.425\right.$; $p<0.001$ vs $\left.R^{2}=0.228 ; p=0.002\right)$. However, this difference was not statistically significant (test of interaction, $p=0.267$ ). The effects from the various examined neonatal variables on the total HRCT score did not differ significantly between the two birth cohorts (tests of interaction).

Compared with subjects without BPD or with only mild BPD $(n=53)$, subjects with a history of moderate or severe BPD $(\mathrm{n}=21)$ had a significantly higher total HRCT score (mean 3.0 vs 5.2, $p=0.009)$ as well as more opacities $(p=0.035)$ and hypoattenuated areas $(p=0.007)$.

Intrauterine cigarette exposure, evidence of maternal infection, antenatal treatment with corticosteroids and treatment with exogenous surfactant were unrelated to HRCT findings at follow-up in simple regression models and when tested with non-parametric group comparisons (Mann-Whitney U test). In simple regression models, gestational age at birth was associated with total HRCT score $(\beta=-0.721 ; 95 \%$ confidence interval (CI) -1.144 to $-0.297 ; p=0.001)$ - that is, one week longer pregnancy reduced the total HRCT score by 0.7 points. Birth weight was also associated with the total HRCT score $(\beta=-0.004 ; 95 \%$ CI -0.007 to $-0.001 ; p=0.013)$-that is, an increase in birth weight of $100 \mathrm{~g}$ reduced the total HRCT score by 0.4 points. A neonatal history of an artificially closed ductus arteriosus was associated with increased total HRCT 
Table 4 Simple linear regression models of total HRCT score and linear/triangular opacities score with respect to lung function variables $(n=74)$

\begin{tabular}{|c|c|c|c|c|c|c|}
\hline & \multicolumn{3}{|c|}{ Linear/triangular opacities } & \multicolumn{3}{|c|}{ Total HRCT score } \\
\hline & $\beta$ & $\mathbf{R}^{2}$ & p Value & $\boldsymbol{\beta}$ & $\mathbf{R}^{2}$ & p Value \\
\hline $\mathrm{FEV}_{1}$ & -0.028 & 0.055 & 0.044 & -0.090 & 0.169 & $<0.001$ \\
\hline $\mathrm{FEF}_{25-50}$ & -0.027 & 0.128 & 0.002 & -0.427 & 0.183 & $<0.001$ \\
\hline $\mathrm{FEF}_{50}$ & -0.030 & 0.173 & $<0.001$ & -0.063 & 0.236 & $<0.001$ \\
\hline RV/TLC* & 0.072 & 0.075 & 0.021 & 0.149 & 0.101 & $<0.001$ \\
\hline
\end{tabular}

Variables of lung function are explanatory variables whereas linear/triangular opacities (0-6) and total HRCT score (0-50) are response variables. Except for the ratio RV/TLC, lung function variables are expressed as percentages of predicted values. Briefly, the $\beta$ values describe the effect from one unit change in the explanatory variable on the response variable.

* Four preterm individuals were unable to enter the plethysmograph, implying $n=70$ for RV/TLC.

$\mathrm{FEV}_{1}$, forced expiratory volume in $1 \mathrm{~s} ; \mathrm{FEF}_{25-50}, \mathrm{FEF}_{50}$, forced expiratory flow at $25-50 \%$ and $50 \%$ of forced vital capacity; $\mathrm{RV}$, residual volume; TLC, total lung capacity.

score $(\beta=1.962 ; 95 \%$ CI 0.573 to $3.350 ; p=0.006)$. Postnatal treatment with corticosteroids significantly predicted increased scores for the most common HRCT findings, and the total HRCT score increased by 4 points in the treated group $(\beta=4.182 ; 95 \%$ CI 2.511 to $5.852 ; \mathrm{p}<0.001)$. The number of days with ventilator treatment was associated with the total HRCT score ( $\beta=0.114 ; 95 \%$ CI 0.066 to $0.163 ; p<0.001$ )-that is, 10 ventilator days increased the total HRCT score by 1.1 points. Increased number of days with oxygen treatment predicted an increase in the total HRCT score as well as more opacities and hypoattenuated areas. Four weeks of oxygen treatment increased the total HRCT score at follow-up by 1 point ( $\beta=0.038 ; 95 \%$ CI 0.025 to $0.052 ; p<0.001)$.

Neonatal variables that were significantly associated with the total HRCT score were included in a backward stepwise linear regression analysis. The final model contained only two variables significant at the $5 \%$ level: number of days with oxygen treatment $(\beta=0.029 ; 95 \%$ CI 0.012 to 0.045$)$ and number of days with ventilator treatment $(\beta=0.060 ; 95 \%$ CI 0.005 to 0.115 ). This model explained $33.3 \%$ of the variability in total HRCT score (adjusted $R^{2}=0.330, p<0.001$ ). When the number of days with ventilator treatment was omitted from the model, the number of days with oxygen treatment still explained $31 \%$ of the variability in total HRCT score $\left(R^{2}=0.307, p<0.001\right)$, thus appearing the single most important explanatory variable after adjustment for other colinear neonatal variables.

\section{Association of HRCT findings with lung function tests}

When studied with simple linear regression models, all of the assessed lung function variables $\left(\mathrm{FEV}_{1}, \mathrm{FEF}_{50}\right.$ and $\mathrm{FEF}_{25-75}$ and the ratio RV/TLC) were significantly associated with linear/ triangular opacities and with total HRCT score (table 4). Reducing $\mathrm{FEV}_{1}$ (expressed as percentage predicted) by 20 units implied an increase in total HRCT score of 1.8 points $(\beta=-0.090 ; 95 \%$ CI -0.14 to $-0.04 ; p<0.001)$. Twenty-one preterm individuals (28\%) had hypoattenuated areas on inspiration and/or expiration images. Subjects with hypoattenuated areas had significantly lower $\mathrm{FEV}_{1}$ than those without hypoattenuated areas (mean $\mathrm{FEV}_{1} 80.9 \%$ vs $89.8 \%$, $p=0.040$ ). No statistical difference was demonstrated between the two groups for mean $\mathrm{FEF}_{50}(74.0 \%$ vs $81.0 \% ; \mathrm{p}=0.289)$ and the ratio $\mathrm{RV} / \mathrm{TLC}(22.8$ vs $22.2 ; \mathrm{p}=0.772)$.

\section{DISCUSSION}

Pulmonary HRCT abnormalities were demonstrated in $86 \%$ of the children or adolescents born extremely preterm, most of the findings being relatively minor with linear/triangular opacities being the most typical (seen in $82 \%$ ). Neonatal BPD and prolonged requirement for oxygen treatment appeared to be the major neonatal predictors for the observed HRCT changes at ages 10 or 18 years. Lung function abnormalities were associated with pathology on pulmonary HRCT scans.

The strengths of this study were the population-based design and the high follow-up rate of $86 \%$. Selection bias is considered unlikely since Haukeland University Hospital provides the only neonatal intensive care unit within the area under investigation. Furthermore, no major differences in baseline characteristics were seen for the cases excluded from the study compared with those included. Two birth cohorts were studied, born approximately 7-8 years apart. To the benefit of all preterm children, but particularly the most immature and vulnerable infants, substantial improvements in treatment had occurred during this time interval. A tendency for increased survival rates in the second birth cohort combined with lower birth weight and gestational age indicate a possible recruitment of new and more immature survivors in the last birth cohort. One may envisage two possible long-term consequences from this scenario: fewer sequelae due to better treatment or more sequelae due to survival of more vulnerable individuals. Interestingly, we observed a non-significant trend for fewer structural pulmonary sequelae in the most recent birth cohort, illustrated by a mean total HRCT score of 3.2 compared with 4.0 in the 1982-5 birth cohort. It cannot readily be established in this study whether or not this numerical difference reflects a true improvement or whether the two birth cohorts are, in fact, similar because of a relatively low power caused mainly by a high degree of individual differences, with a consequently wide range of distribution (mean (SD) total HRCT score 3.6 (3.0)). With this knowledge at hand, we have in retrospect calculated that the lower detection limit of this study for differences between the two birth cohorts was approximately 2 points for total HRCT score, providing a significance level of 0.05 and $80 \%$ power. Subanalyses of putative associations between particular neonatal variables and particular HRCT subscores would be even more difficult to interpret. Larger multicentre studies or metaanalyses are required to investigate these issues.

A slightly revised procedure for calculating the HRCT scores was used in this study compared with a previous presentation of these same subjects. ${ }^{9}$ First, linear and triangular opacities were merged into one entity as these findings may be difficult to distinguish and may also reflect similar pathology. Second, we opted to base the scores on findings in the different lung lobes instead of lung segments. This made the scoring process less complex, reducing the risk of inaccuracies. Furthermore, the highest attainable score of this revised version becomes more evident to an uninvolved clinician. Formal reliability testing was 
not felt to be required as the revised version is fully based on the previous and more complex method.

Histopathological findings after extremely preterm birth typically include abnormal alveolarisation, disturbed vascularisation and altered elastic and fibrous interstitial networks. ${ }^{19-23}$ This again may change the peribronchiolar support, elastic recoil and small airway resistance and lead to decreased expiratory flow rates. ${ }^{24}{ }^{25}$ The reduced maximal expiratory flow rates $\left(\mathrm{FEV}_{1}, \mathrm{FEF}_{50}\right.$ and $\left.\mathrm{FEF}_{25-75}\right)$ observed in our study may be explained within this conceptual framework. Further, the observed association between low flow rates and HRCT changes suggests that the radiographic findings, although subtle, reflect some fundamental aspect of the pulmonary sequelae from extremely preterm birth.

The neonatal history of extreme preterm individuals varies considerably, some being relatively benign while, in others, neonatologists are faced with major challenges from nearly all organ systems. In these tiny patients, most medical problems tend to be interrelated and have some impact on ventilation and gas exchange. We know, for instance, that a neonate born with a low birth weight after a short gestation who develops respiratory distress and a wide open ductus arteriosus is likely to be exposed to prolonged mechanical ventilation, postnatal corticosteroids, some procedure to close the patent ductus arteriosus and prolonged oxygen treatment. The long-term effects of particular neonatal factors are therefore difficult to discern due to co-linearity between the explanatory variables.

Clearly, pulmonary outcome from premature birth is related to gestational age at birth and to birth weight. ${ }^{26}{ }^{27}$ In simple regression analyses in this study, these variables were also related to the total HRCT score. We also observed a strong association between postnatal treatment with corticosteroids and HRCT findings. Grischkan et $a l^{28}$ reported a similar association with subsequent development of asthma. In this context, one must bear in mind that this treatment is used to facilitate extubation in infants with the most severe lung disease. In a stepwise multiple regression model including a series of potential explanatory variables, the number of days with oxygen treatment and the number of days with ventilator treatment explained $33.3 \%$ of the variability in total HRCT score, supporting the view that the most traumatised neonates are those most prone to develop long-term sequelae.

Prolonged requirements for oxygen treatment have previously been identified as an important explanatory variable for functional lung abnormalities. ${ }^{10-12}$ This study provides evidence that this association is present also for structural lung sequelae as evident on HRCT scanning. Whether or not this is a noxious effect of oxygen per se is unknown. Certainly, prolonged requirements for supplemental oxygen may represent the "final common output" of a series of events, inducing a statisticalbut not necessarily a causal-relation to outcome. However, an independent noxious effect from oxygen is not biologically implausible. Both scenarios may be true-that is, prolonged requirements may be a marker of lung injury already present as well as a causal factor for additional lung injury. Whatever role oxygen supplementation may play, prolonged requirements appear to be a prognostic indicator for subsequent functional and structural abnormalities in these infants.

Only a few studies have reported the HRCT findings in longterm survivors of preterm birth, ${ }^{29-34}$ of which only two address the associations between HRCT findings and neonatal factors and lung function. ${ }^{31}{ }^{32}$ In a study by Mahut and colleagues, ${ }^{31}$ which included 41 toddlers aged between 10 and 20 months with a history of neonatal BPD and uncontrolled respiratory symptoms, pathological HRCT findings were reported in all cases with a higher prevalence of opacities and hyperlucent areas than in our study. Their findings of prolonged neonatal oxygen treatment predicting later HRCT abnormalities, as well as the positive association between HRCT pathology and reduced lung function, are consistent with our findings. Wong and colleagues reported pulmonary emphysema on HRCT images in 16 out of 19 ex-preterm individuals who had a neonatal history of oxygen requirements at 36 weeks gestation and were examined at the age of 18-26 years. ${ }^{32}$ However, their cohort was highly selected, constituting 19 subjects (14\%) from a cohort consisting of 133 subjects.

Bancalari et al reported that the fraction of infants able to breathe room air at 36 weeks was relatively similar over a wide range of gestational ages. ${ }^{4}$ Since infants born after a short gestation require longer periods of oxygen therapy to reach 36 weeks than more mature infants, increased survival in the most immature group seems to occur at the cost of prolonged exposure to oxygen treatment. Although not statistically significant, prolonged treatment with oxygen seemed to be more important for total HRCT score in the 1991-2 birth cohort than in the $1982-5$ cohort. If prolonged oxygen exposure is a principal explanatory factor for subsequent functional as well as structural abnormalities of the lungs, one may reason that increased survival of the most immature infants may occur at the cost of an increased risk of long-term pulmonary sequelae.

In conclusion, in area-based cohorts of 10-18-year-old subjects born extremely preterm in the 1980-90s, evidence of structural lung injury was observed on HRCT images in $86 \%$ of the subjects, the majority of the pathology being relatively minor linear or subpleural opacities. A neonatal history of prolonged requirements for oxygen treatment predicted subsequent structural abnormalities on the HRCT scan, as well as lung function abnormalities. Structural and functional pulmonary abnormalities were significantly associated with each other, suggesting that these outcome categories are related and possibly connected to similar neonatal traumas.

Acknowledgements: The authors are indebted to Professor Trond Markestad for his enthusiasm and valuable comments.

Competing interests: None.

Ethics approval: The Regional Committee for Medical Research Ethics approved the study. Informed written consent was obtained from participating subjects and parents.

\section{REFERENCES}

1. Hack M, Fanaroff AA. Outcomes of children of extremely low birthweight and gestational age in the 1990s. Semin Neonatol 2000:5:89-106.

2. Hack M, Horbar JD, Malloy $\mathrm{MH}$, et al. Very low birth weight outcomes of the National Institute of Child Health and Human Development Neonatal Network. Pediatrics 1991;87:587-97.

3. Markestad T, Kaaresen Pl, Ronnestad A, et al. Early death, morbidity, and need of treatment among extremely premature infants. Pediatrics 2005;115:1289-98.

4. Bancalari E, Claure N, Sosenko IR. Bronchopulmonary dysplasia: changes in pathogenesis, epidemiology and definition. Semin Neonatol 2003;8:63-71.

5. Allen J, Zwerdling R, Ehrenkranz R, et al. Statement on the care of the child with chronic lung disease of infancy and childhood. Am J Respir Crit Care Med 2003;168:356-96.

6. Baraldi E, Filippone M. Current concepts: chronic lung disease after premature birth. N Engl J Med 2007;357:1946-55.

7. Shaheen So, Barker DJ, Holgate ST. Do lower respiratory tract infections in early childhood cause chronic obstructive pulmonary disease? Am J Respir Crit Care Med 1995;151:1649-51.

8. Wohl ME. Bronchopulmonary dysplasia in adulthood. N Engl J Med 1990;323:1834-6.

9. Aukland SM, Halvorsen T, Fosse KR, et al. High-resolution CT of the chest in children and young adults who were born prematurely: findings in a population-based study. Am J Roentgenol 2006;187:1012-8.

10. Halvorsen T, Skadberg BT, Eide GE, et al. Pulmonary outcome in adolescents of extreme preterm birth: a regional cohort study. Acta Paediatr 2004;93:1294-300.

11. Halvorsen T, Skadberg BT, Eide GE, et al. Better care of immature infants: has it influenced long-term pulmonary outcome? Acta Paediatr 2006;95:547-54. 
12. Kennedy JD, Edward LJ, Bates DJ, et al. Effects of birthweight and oxygen supplementation on lung function in late childhood in children of very low birth weight. Pediatr Pulmonol 2000;30:32-40.

13. Jobe AH, Bancalari E. Bronchopulmonary dysplasia. Am J Respir Crit Care Med 2001;163:1723-9.

14. Sola A, Kurlat I, Pollak A, et al. Early versus delayed neonatal administration of a synthetic surfactant: the Judgment of Osiris. Lancet 1992;340:1363-9.

15. Quanjer PH, Tammeling GJ, Cotes JE, et al. Lung volumes and forced ventilatory flows. Report Working Party Standardization of Lung Function Tests European Community for Steel and Coal. Official Statement of the European Respiratory Society. Eur Respir J 1993:6:5-40.

16. Quanjer PH, Borsboom GJJM, Brunekreef B, et al. Spirometric reference values for white European children and adolescents: Polgar revisited. Pediatr Pulmonol 1995:19:135-42.

17. Knudson RJ, Lebowitz MD, Holberg CJ, et al. Changes in the normal maximal expiratory flow-volume curve with growth and aging. Am Rev Respir Dis 1983;127:725-34.

18. Pocock SJ, Collier TJ, Dandreo KJ, et al. Issues in the reporting of epidemiological studies: a survey of recent practice. BMJ 2004;329:883-7.

19. Coalson JJ. Pathology of new bronchopulmonary dysplasia. Semin Neonatol 2003;8:73-81.

20. Husain AN, Siddiqui NH, Stocker JT. Pathology of arrested acinar development in postsurfactant bronchopulmonary dysplasia. Hum Pathol 1998;29:710-7.

21. Albertine $\mathbf{K H}$, Jones $\mathrm{CP}$, Starcher $\mathrm{BC}$, et al. Chronic lung injury in preterm lambs: disordered respiratory tract development. Am J Respir Crit Care Med 1999;159:94558.

22. Pierce RA, Albertine $\mathrm{KH}$, Starcher $\mathrm{BC}$, et al. Chronic lung injury in preterm lambs: disordered pulmonary elastin deposition. Am J Physiol Lung Cell Mol Physiol 1997;16:L452-60.
23. Thibeault DW, Mabry SM, Ekekezie II, et al. Collagen scaffolding during development and its deformation with chronic lung disease. Pediatrics 2003;111:766-76.

24. Bellofiore S, Eidelman DH, Macklem PT, et al. Effects of elastase-induced emphysema on airway responsiveness to methacholine in rats. J Appl Physiol 1989;66:606-12.

25. Mead J, Turner JM, Macklem PT, et al. Significance of relationship between lung recoil and maximum expiratory flow. J Appl Physiol 1967;22:95-108

26. Anand D, Stevenson CJ, West CR, et al. Lung function and respiratory health in adolescents of very low birth weight. Arch Dis Child 2003:88:135-8.

27. Rona RJ, Gulliford MC, Chinn S. Effects of prematurity and intrauterine growth on respiratory health and lung function in childhood. BMJ 1993;306:817-20.

28. Grischkan J, Storfer-Isser A, Rosen CL, et al. Variation in childhood asthma among former preterm infants. J Pediatr 2004;144:321-6.

29. Aquino SL, Schechter MS, Chiles C, et al. High-resolution inspiratory and expiratory $\mathrm{CT}$ in older children and adults with bronchopulmonary dysplasia. AJR Am J Roentgenol 1999:173:963-7.

30. Ochiai M, Hikino $\mathrm{S}$, Yabuuchi $\mathrm{H}$, et al. A new scoring system for computed tomography of the chest for assessing the clinical status of bronchopulmonary dysplasia. J Pediatr 2008;152:90-5.

31. Mahut B, de Blic J, Ernond S, et al. Chest computed tomography findings in bronchopulmonary dysplasia and correlation with lung function. Arch Dis Child Fetal Neonatal 2007:92:459-64

32. Wong PM, Lees AN, Louw J, et al. Emphysema in young adult survivors of moderate to severe bronchopulmonary dysplasia. Eur Respir J 2008;32:321-8.

33. Howling SJ, Northway WH Jr, Hansell DM, et al. Pulmonary sequelae of bronchopulmonary dysplasia survivors: high-resolution CT findings. AJR Am J Roentgenol 2000;174:1323-6.

34. Oppenheim C, Mamou-Mani T, Sayegh N, et al. Bronchopulmonary dysplasia: value of CT in identifying pulmonary sequelae. AJR Am J Roentgenol 1994;163:169-72.

\section{Lung alert}

\section{Long-term effects of tiotropium in COPD}

Long-acting inhaled anticholinergic agents are a mainstay of treatment in chronic obstructive pulmonary disease (COPD) and have a beneficial effect on many clinical outcomes. This study examined the long-term benefits and safety of tiotropium in COPD, particularly the rate of decline of forced expiratory volume in $1 \mathrm{~s}\left(\mathrm{FEV}_{1}\right)$.

In a multinational double-blind placebo controlled trial, patients were randomised to receive tiotropium or placebo in addition to all their other respiratory medications (excluding other anticholinergic agents). Patients were included if they were over the age of 40 with a diagnosis of COPD. Patients with asthma, those with an exacerbation of COPD in the preceding month and those on long-term oxygen therapy were excluded.

There was no significant difference in the yearly decline of $\mathrm{FEV}_{1}$ between the two groups. However, there was a significant rate of decline in those that prematurely left the study and these individuals were more likely to be in the placebo group. Tiotropium significantly reduced exacerbations, hospitalisations and respiratory failure compared with placebo and also improved health-related quality of life. Serious cardiac adverse events, including myocardial infarction and cardiac failure, were significantly reduced in the tiotropium arm.

The authors concluded that, although tiotropium had no effect on reducing the rate of decline of lung function in COPD, there were other beneficial effects. The low cardiac adverse event rates at follow-up are also reassuring in view of a recently published meta-analysis, although further studies must be conducted to clarify this issue.

- Tashkin DP, Celli B, Senn S, et al for the UPLIFT Study Investigators. A 4-year trial of tiotropium in chronic obstructive pulmonary disease. N Engl J Med 2008;359:1543-54.

\section{N Pareek}

Correspondence to: Dr N Pareek, ST2 Respiratory Medicine, Royal Brompton Hospital, London, UK; nilpareek@gmail.com 